Journal of Applied Fluid Mechanics, Vol. 14, No. 5, pp. 1547-1558, 2021. Available online at www.jafmonline.net, ISSN 1735-3572, EISSN 1735-3645. https://doi.org/10.47176/jafm.14.05.32454

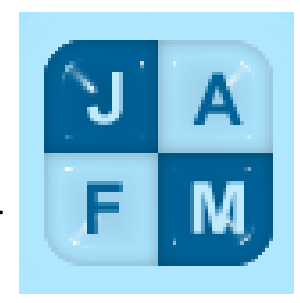

\title{
CFD Study on the Efficacy of Flow Diverter Stent Placement for Cerebral Aneurysms
}

\author{
Y. Ito ${ }^{\dagger}$, I. Cho, Y. Sakai and K. Iwano \\ Department of Mechanical Systems Engineering, Nagoya University, Furo-cho, Chikusa-ku, Nagoya, \\ 464-8603, Japan \\ $\dagger$ Corresponding Author Email: yito@nagoya-u.jp
}

(Received December 8, 2020; accepted April 5, 2021)

\begin{abstract}
The effect of flow diverter (FD) stent placement as a cerebral aneurysm treatment on hemodynamics was systematically investigated via numerical simulation. The aneurysm diameter was set to $8 \mathrm{~mm}$ and $12 \mathrm{~mm}$, with an aspect ratio $(A R)$ of 1.2 and 1.9, respectively. The curvature of the parent artery was also varied for the following three types: straight, inside, and outside. The blockage ratio of the FD stent was set to $31 \%$. The results reveal that, regardless of artery shape, the FD stent drastically modifies the flow in the aneurysm, including changing the flow direction in the systolic phase. In most cases, the flow rate into the aneurysm is significantly reduced by the stent; however, in the case of a straight artery, the flow rate is increased for the aneurysm model with $A R=1.9$. The oscillatory shear index (OSI) generally increases owing to FD stent placement while the wall shear stress is substantially decreased. In particular, a high OSI area is widely distributed in the large aneurysm sac $(A R=1.9)$ for straight and internal artery cases. Although idealized aneurysm models are employed in the present study and further parametric studies are required, particularly with respect to stent configuration, these facts may explain the unexpected outcome in some (but not all) large aneurysm cases.
\end{abstract}

Keywords: Cerebral aneurysm; CFD; Flow diverter stent; Hemodynamics; Flow rate.

\section{NOMENCLATURE}

$\begin{array}{ll}A & \text { neck area } \\ A R & \text { aspect ratio of the aneurysm } \\ d & \text { diameter of the parent vessel } \\ D & \text { diameter of the aneurysm } \\ i, j, k & \text { directions } \\ N & \text { neck width } \\ \text { OSI } & \text { oscillatory shear index } \\ p & \text { fluid pressure } \\ q & \text { instantaneous inflow rate to the aneurysm }\end{array}$

$\begin{array}{ll}Q & \text { mean inflow rate to the aneurysm } \\ r & \text { radius of curvature } \\ T & \text { cardiac cycle } \\ \text { wss } & \text { instantaneous wall shear stress } \\ \text { WSS } & \text { Mean Wall Shear Stress } \\ x, y, z & \text { directions } \\ \mu & \text { fluid viscosity } \\ \rho & \text { fluid density }\end{array}$

\section{BACKGROUND}

A cerebral aneurysm is a balloon-like dilation that forms on an artery in the brain and its rupture often leads to critical complications, including loss of life. For example, Connlly et al. (2012) reported that the mortality of aneurysm rupture can be as high as 50 $\%$ and $25 \%$ of survivors suffer from secondary diseases.

Several medical treatments have been proposed to prevent aneurysm rupture. The surgical clipping technique, in which the aneurysm neck is clipped by

a small clip to stop the inflow of blood and promote clot formation, has been widely recognized as a promising method. However, it is essentially a craniotomy procedure, which places a heavy strain on patients. Moreover, particular attention needs to be paid to other risks, such as infections. In this respect, endovascular treatments are less invasive and less stressful; therefore, they have become more common. Coil embolization is the most popular method (Goel et al. 2014; McDonald et al. 2014; Pierot et al. 2014; Piotin et al. 2010). Insertion of coils into the aneurysm makes the flow in the aneurysm inactive and promotes clotting. However, 
the coils may dislocate, particularly in cases of wide neck and/or large aneurysms (Ishihara et al. 2015; Soeda et al. 2003). It has also been reported that recanalization occurs in some cases, probably because the coils are pushed to the bottom of the aneurysm and, therefore, the clot is not well formed (Cognard et al. 1999; Grunwald et al. 2007; Shapiro et al. 2012).

In contrast, flow diverter (FD) stent treatment has become a popular endovascular technique (Lylyk et al. 2009; Piano et al. 2013; Sadasivan et al. 2009; Berge et al. 2012; De Vries et al. 2013; Aenis et al. 1997; Anzai et al. 2014; Seong et al. 2007; Seshadhri et al. 2011; Chong et al. 2014; Mori et al. 2014; Dholakia et al. 2014; Fischer et al. 2012; Lubcz et al. 2011; Torres et al. 2018; Möhlenbruch et al. 2015; Nelson et al. 2011; Saatci et al. 2012; Lai et al. 2016; Meng et al. 2006; Imai et al. 2008; Kim et al. 2008; Korkmazer et al. 2019). The FD stent has a high blockage ratio and is placed in the parent artery to cover the neck of the aneurysm. The basic strategy is to block blood flow into the aneurysm and make the flow in the aneurysm inactive without a coil (Anzai et al. 2014; Seong et al. 2007; Seshadhri et al. 2011; Chong et al. 2014; Mori et al. 2014; Dholakia et al. 2014). In addition to advantages, such as technical simplicity and minimal invasiveness, this method has also been recognized as a promising treatment in several clinical studies (Lylyk et al. 2009; Piano et al. 2013; Sadasivan et al. 2009; Berge et al. 2012; De Vries et al. 2013; Fischer et al. 2012; Lubcz et al. 2011; Torres et al. 2018; Möhlenbruch et al. 2015; Nelson et al. 2011; Saatci et al. 2012; Bouillot et al. 2015; Jiayao et al. 2013; Lubicz et al. 2011). Piano et al. (2013) reported that $86 \%$ of the evaluated aneurysms were completely occluded within 6 months and no recanalization was observed in these cases. De Vries et al. (2013) investigated a total of 49 aneurysms in 37 patients and found that $94 \%$ of the stented aneurysms exhibited complete occlusion within 6 months. Saatci et al. (2012) treated 191 patients with 251 aneurysms. In this series of studies, more than $90 \%$ of aneurysms were successfully occluded by applying a flow-diverting device. Efforts to determine optimal configurations have been conducted in previous studies (Bouillot et al. 2015, Jiayao et al. 2013).

However, several clinical studies (Turowski et al. 2011; Kulcsar et al. 2011; Mustafa et al. 2010; Rouchaud et al. 2016; Cruz et al. 2012; Brinjikji et al. 2013; Lubicz et al. 2010; Briganti et al. 2012; Siddiqui et al. 2012; Cagnazzo et al. 2019) reported unsuccessful cases or found some negative phenomena. Kulcsar et al. (2011) investigated 13 cases of delayed rupture. They found that most ruptured aneurysms were large and had high aspect ratios. Similarly, Rouchaud et al. (2016) reported that approximately half of the delayed ruptured aneurysms were large. Furthermore, some fundamental studies (Cagnazzo et al. 2019; Liou et al. 2008; Bouillot et al. 2015; Cebral et al. 2011) have shown that the effects of FD stents on hemodynamics are complex. Liou et al. (2008) and Bouillot et al. (2015) showed that the locations of inflow and outflow at the systolic phase swap owing to the placement of the FD stent in the artery. Cebral et al. (2011) concluded that FD stent placement can drastically elevate the pressure in the aneurysm, which may lead to delayed rupture. A recent study by Larrabide et al. (2016) indicated that FD stent treatment significantly increased the flow pulsatility in the aneurysm.

These findings indicate that FD stent placement can result in unexpected outcomes in some cases. As shown above, delayed rupture is likely to occur in large aneurysms but not all large aneurysms rupture; i.e., the size of the aneurysm is not the only factor of importance. For instance, previous studies (Cebral et al. 2011; Ujiie et al. 2011) pointed out that aneurysm rupture was triggered by blebs. However, this does not mean that no rupture occurs if a bleb is not formed. Generally, every aneurysm has a unique configuration and small differences may cause major differences. Some studies (Matsuda et al. 2017; Tateshima et al. 2003) indicate that numerical analysis dealing with simplified models can be significantly different from what is observed in practice. However, it is also true that it is still beneficial to simulate such idealized flows to clarify the hemodynamics from more fundamental and general aspects and several numerical studies have found a variety of interesting and significant results (Rajah et al. 2017; Vargas et al. 2016; Bhogal et al. 2017; Walcott et al. 2016).

Thus, we conducted systematic CFD simulations of typical round aneurysm models, with two different sizes formed on the side of a parent artery with three different curvatures. Our goal was to investigate the impact of the FD stent on hemodynamics and related parameters and to clarify the configurations of the aneurysm and parent vessel that may lead to unexpected outcomes.

\section{NUMERICAL METHODS}

\subsection{Aneurysm and Artery Configurations}

The outline of the present CFD simulations is the same as that in our previous work (Matsuda et al. 2017), in which the accuracy of the simulation was validated by comparing it with PIV experiments. The schematics of the computational domain are shown in Fig. 1. Figure 1(a) shows the aneurysm model. It has a spherical shape with a diameter of $\mathrm{D}=8 \mathrm{~mm}$ or $\mathrm{D}=12 \mathrm{~mm}$. Both models have a neck width of $\mathrm{N}=5.66 \mathrm{~mm}$ and the parent vessel diameter is set to $\mathrm{d}=4.0 \mathrm{~mm}$. Here, the aspect ratio $(A R)$, defined by $\mathrm{H} / \mathrm{N}$, where $\mathrm{H}$ is the depth of the aneurysm, is $A R=1.2$, and $A R=1.9$, for $\mathrm{D}=8 \mathrm{~mm}$ and $12 \mathrm{~mm}$, respectively. According to a clinical study by Ujiie et al. (Ujiie et al. 2011), $80 \%$ of aneurysms with $A R>1.6$ ruptured whereas $90 \%$ of aneurysms with $A R<1.6$ remained unruptured. The fluid flows in and out from the left and right sides of the image, respectively. Note that the artery is sufficiently long to avoid influences from the inlet and outlet boundaries. Figure 1(b) shows the three tested parent artery shapes; the first from the left shows a straight artery and the second and third shapes have curves with radii of curvature of $r=-9.55 \mathrm{~mm}$ and $r=+9.55$ 
mm, respectively. In other words, for $r=-9.55$ the curve is on the aneurysm side while for $r=+9.55$ $\mathrm{mm}$, the shape curves away from the aneurysm. In the present study, these three cases are referred to as straight, inside, and outside artery cases, respectively.

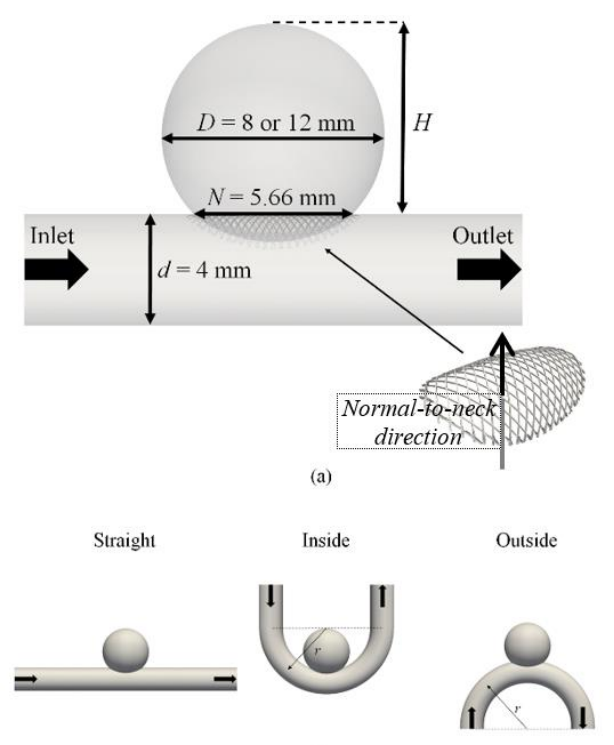

(b)

Fig. 1. Schematics of the computational domain: (a) aneurysm model; (b) parent artery shapes.

With respect to the configuration of the FD stent, one of the pipeline stents (Medtronic) was reproduced as an existing stent. It has a rhombus mesh with a side length of $0.32 \mathrm{~mm}$ and inner angles of $136^{\circ}$ and $44^{\circ}$; therefore, the mesh area is $0.07 \mathrm{~mm}^{2}$. The strut width was $0.045 \mathrm{~mm}$ and the blockage ratio was $31 \%$. In the simulation, a flat mesh satisfying the configuration was rolled along the artery wall. Note that it was placed only at the neck area of the aneurysm to reduce the computational load.

\subsection{Computational Mesh}

Star-CCM+ was used to create the computational mesh, which comprised unstructured tetrahedral elements. The mesh size varied from $0.01 \mathrm{~mm}$ (near the stent struts) to $0.4 \mathrm{~mm}$ (bulk regions) so that the flow and stent struts can be sufficiently resolved. The non-stented models had approximately 4 million to 6 million grid points while the stented models had approximately 22 million to 28 million grid points.

\subsection{Computational algorithm}

Direct numerical simulations based on the finitevolume method were performed using OpenFOAM 2.3.1 (Open CFD Ltd). The governing equations are the continuity equation and Navier-Stokes equation:

$$
\begin{aligned}
& \frac{\partial u_{i}}{\partial x_{i}}=0 \\
& \frac{\partial u_{j}}{\partial t}+\frac{\partial\left(u_{k} u_{j}\right)}{\partial x_{k}}=-\frac{1}{\rho} \frac{\partial p}{\partial x_{j}}+\frac{\mu}{\rho} \frac{\partial^{2} u_{j}}{\partial x_{i} \partial x_{i}},
\end{aligned}
$$

Where $p$ is the pressure, $\rho$ is the density of the fluid, $\mu$ is the viscosity of the fluid, $t$ is time, and $u_{i}(i=1,2,3)$ are the velocity components. The fluid was assumed to be an incompressible Newtonian fluid. The fluid density and viscosity were set to 1050 $\mathrm{kg} / \mathrm{m}^{3}$ and $3.47 \times 10^{-3} \mathrm{~Pa} \cdot \mathrm{s}$, respectively. For the inlet boundary, the pulsatile velocity (Matsuda et al. 2017) was periodically applied to the entire area. The Reynolds number, based on the inlet velocity and diameter of the parent artery, varied from 224 to 565 . The systolic peak appeared at $t / T=0.28$, where $T$ is the cardiac cycle. The Neumann boundary condition with a zero-velocity gradient was applied at the outlet boundary. The pressure boundary condition was set to 0 at the outlet boundary and the Neumann condition was applied at the inlet. The parent artery and aneurysm were regarded as rigid walls and the non-slip condition was applied to the surfaces. The time increment was set as $0.001 \mathrm{~s}$. The simulation was allowed to progress until the flow statistics over a cycle became constant. The data exhibited in the present study were obtained at the 8th cycle in nonstented cases and the 20th cycle in stented cases.

In the present paper, some hemodynamic parameters, such as inflow rate to the aneurysm, $q$, mean wall shear stress, WSS, and oscillatory shear index (OSI) are discussed in the next section. The inflow rate to the aneurysm is defined as follows:

$q=\frac{1}{2} \int_{A}\left|u_{2}\right| d A$,

where $A$ is the neck area and $u_{2}$ is the instantaneous normal-to-neck velocity. With respect to mean wall shear stress

$$
\begin{aligned}
& \mathrm{WSS}=\frac{1}{T} \int_{t}^{t+T}|\mathrm{wss}| d t, \\
& \mathrm{wSs}=\mu \frac{\partial u_{p}}{\partial x_{n}},
\end{aligned}
$$

where wss is the instantaneous wall shear stress at the aneurysm surface, $u_{p}$ is the velocity component parallel to the aneurysm surface, and $x_{n}$ is the direction normal to the aneurysm surface. Finally, the definition of the OSI is as follows:

$$
\mathrm{OSI}=\frac{1}{2}\left\{1-\frac{\left|\int_{0}^{T} \mathrm{wss} d t\right|}{\int_{0}^{T}|\mathrm{wss}| d t}\right\} \text {. }
$$

\section{RESULTS AND DISCUSSION}

\subsection{Flow Field}

First, we show the transition of the velocity field in the aneurysm to capture the flow pattern in each case. Figure 2 shows the instantaneous velocity vectors on the central plane at $t / T=0.25,0.5,0.75$, and 1.0 for 

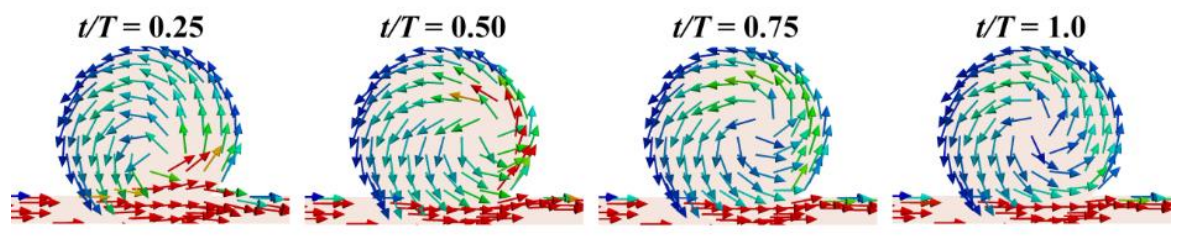

(a) Straight

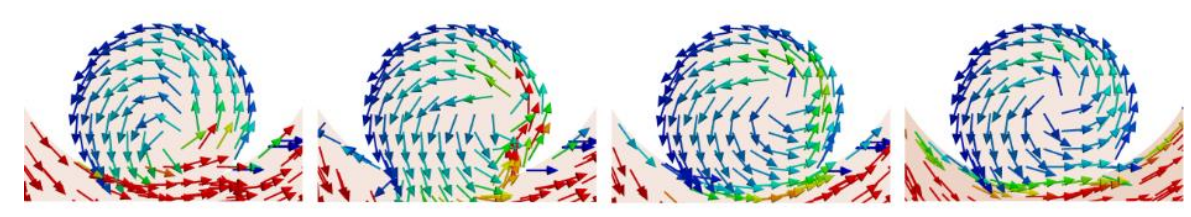

(b) Inside

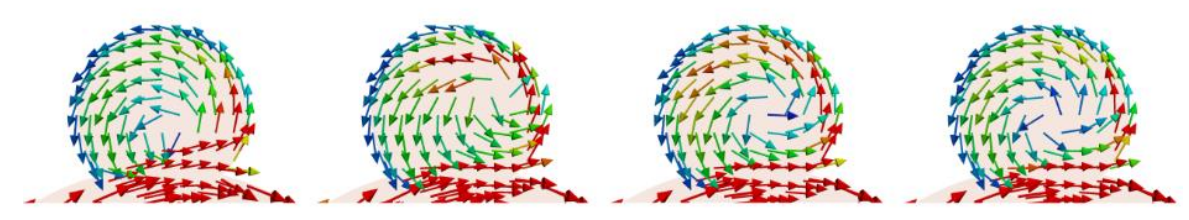

(c) Outside

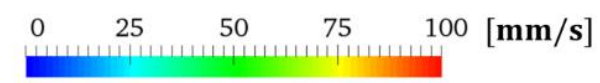

Fig. 2. Instantaneous velocity vectors on the central plane at $t / T=0.25,0.5,0.75$, and 1.0 for the case with the non-stented model and $A R=1.2$.

the non-stented model and $A R=1.2$. Here, Figs. 2(a), 2(b), and 2(c) correspond to the straight, inside, and outside artery cases, respectively. Figure 3 shows the same data as in Fig. 2 but for the non-stented model and $A R=1.9$. Note that the maximum velocity reaches approximately $650 \mathrm{~mm} / \mathrm{s}$ at $t / T=0.25$; however, in these figures, a velocity larger than 100 $\mathrm{mm} / \mathrm{s}$ is shown in red for clearer visualization of the aneurysm. Figure 2 illustrates that a large counterclockwise flow forms in the aneurysm sac, regardless of the differences in artery shape. A notable jet-like inflow on the distal side of the aneurysm was observed in the case of the outside artery. In the case of $A R=1.9$, and the non-stented model (Fig. 3), the flow pattern is approximately similar to that for a non-stented model and $A R=1.2$, as shown in Fig. 2. However, the velocity of the aneurysm was generally smaller. Figures 4 and 5 show the instantaneous velocity vectors on the central plane at $t / T=0.25,0.5,0.75$, and 1.0 , respectively, for the stented model and $A R=1.2$ and 1.9. By comparing Figs. 2 and 4, we find two major effects of the FD stent. The first effect is that the jet flow is substantially weakened and the intraaneurysmal velocity is reduced in all artery shapes. Second, the flow pattern changed drastically. In the cases with the stented model and $A R=1.2$, although there are minor differences among the straight, inside, and outside artery cases, the flow direction in the aneurysm becomes approximately clockwise at $t / T=0.25$; i.e., the flow enters from the proximal side of the neck and flows out from the distal side of the neck. Such modification of the flow pattern by FD stent placement has been reported in previous studies (Liou et al. 2008; Bouillot et al. 2015). At $t / T=0.50$, the flow along the aneurysm surface turns in the counter-clockwise direction but the inner fluid continues flowing in an approximately clockwise direction. At $t / T=0.75$, and 1.0 , the flow pattern becomes more complex and a mixture of counterclockwise and clockwise vortices appears in the aneurysm.

Conversely, for all cases with the stented model and $A R=1.9$ (Fig. 5), the main flow direction becomes clockwise at $t / T=0.25$, which is the same trend as for $A R=1.2$. However, the flow pattern varied depending on the artery shape. In the straight artery case (Fig. 5(a)), two large vortices appear at $t / T=0.50$ but the counter-clockwise flow becomes dominant at $t / T=0.75$, as in the non-stented cases. The latter change is also observed in the internal artery case but from $t / T=0.50$, as shown in Fig. 5(b). In the outside artery case (Fig. 5(c)), the inner clockwise flow is relatively dominant at $t / T=0.5$ but tends to split into clockwise and counter-clockwise vortices at $t / T=1.0$. This is similar to the $A R=1.2$ case shown in Fig. 4(c).

As explained in the Introduction, the primary goal of FD stent placement is to reduce the inflow into the aneurysm. Hence, we calculated the inflow rate to the aneurysm, $q$. Figure 6 shows the time-series data. As indicated in the previous figures, the FD stent generally reduced the inflow rate. In particular, the inflow rate in the systolic phase $(t / T=0.25)$ was significantly reduced in the outside-artery case. 


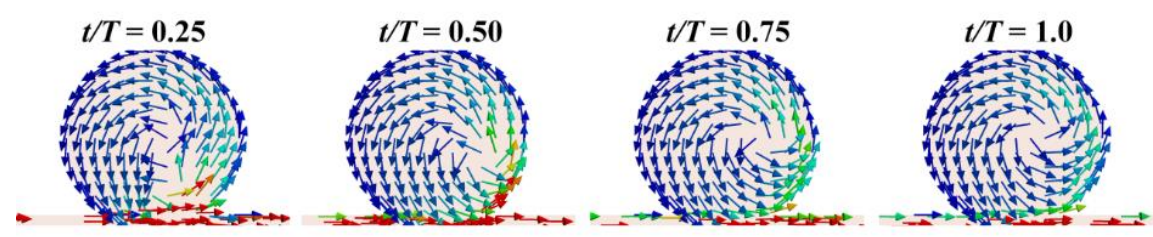

(a) Straight

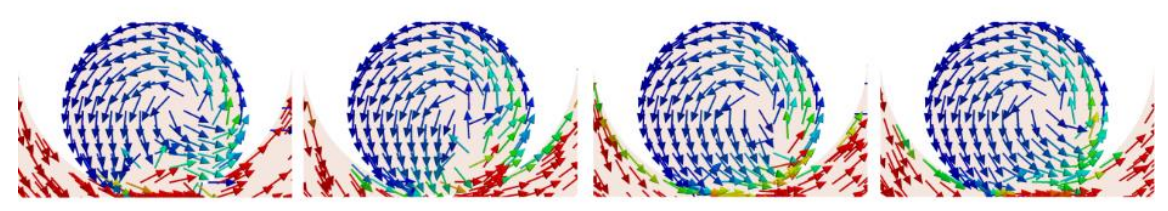

(b) Inside
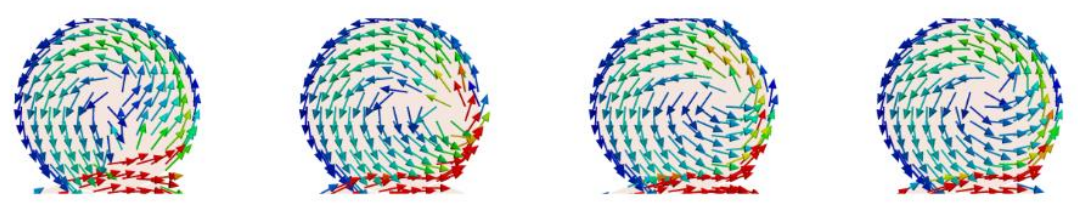

(c) Outside

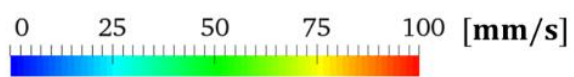

Fig. 3. Instantaneous velocity vectors on the central plane at $t / T=0.25,0.5,0.75$, and 1.0 for the case with the non-stented model and $A R=1.9$.

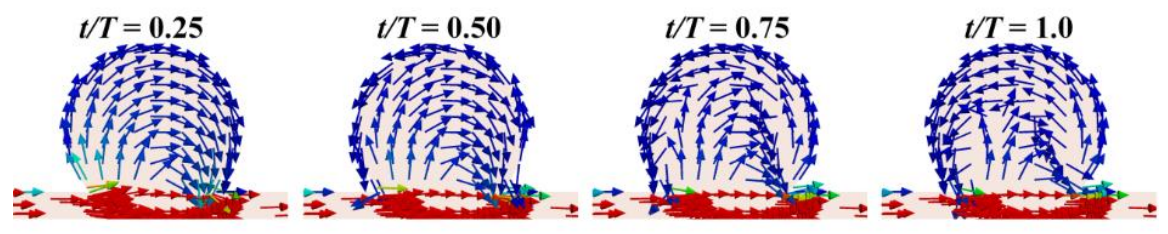

(a) Straight

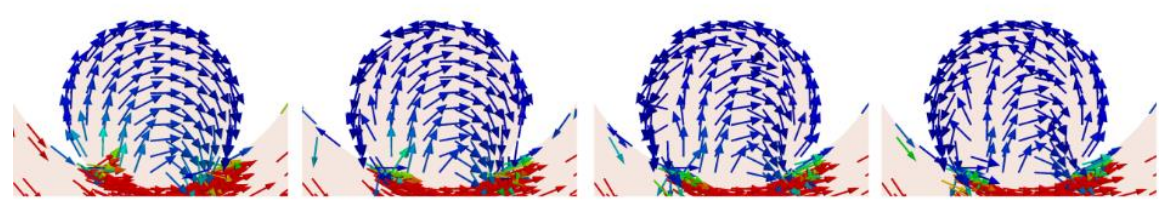

(b) Inside

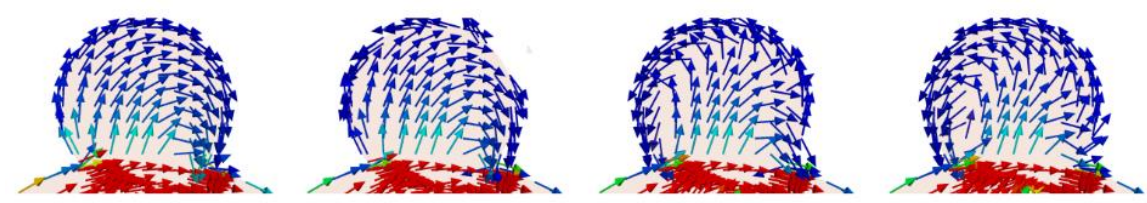

(c) Outside

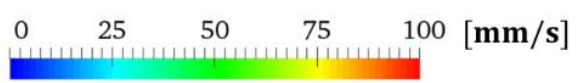

Fig. 4. Instantaneous velocity vectors on the central plane at $t / T=0.25,0.5,0.75$, and 1.0 for the case with the stented model and $A R=1.2$. 

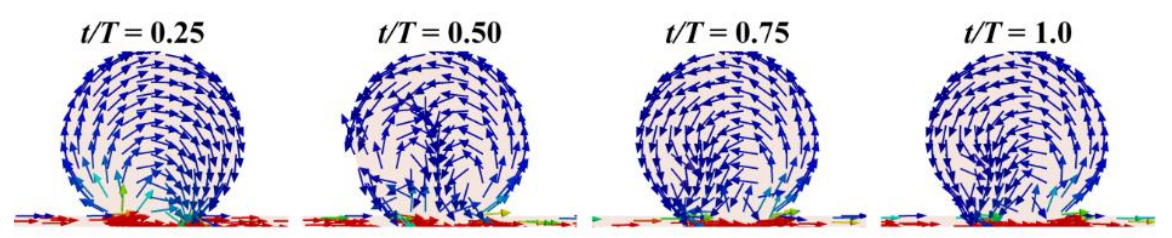

(a) Straight

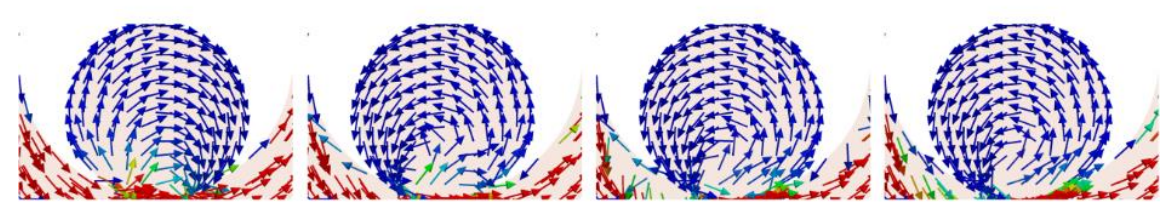

(b) Inside
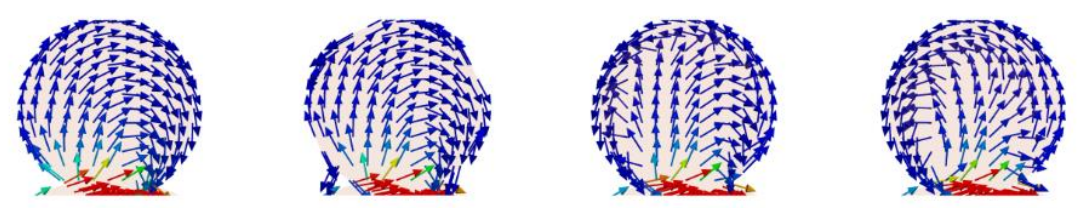

(c) Outside

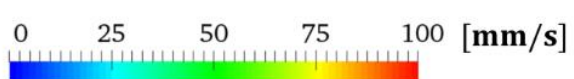

Fig. 5. Instantaneous velocity vectors on the central plane at $t / T=0.25,0.5,0.75$, and 1.0 for the case with the stented model and $A R=1.9$.
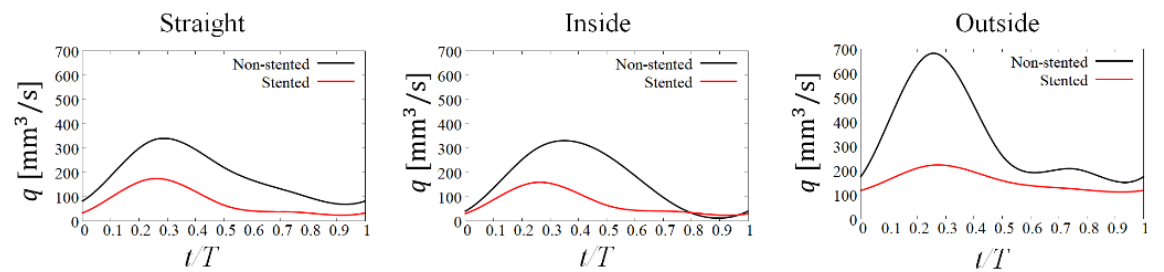

(a) $A R=1.2$
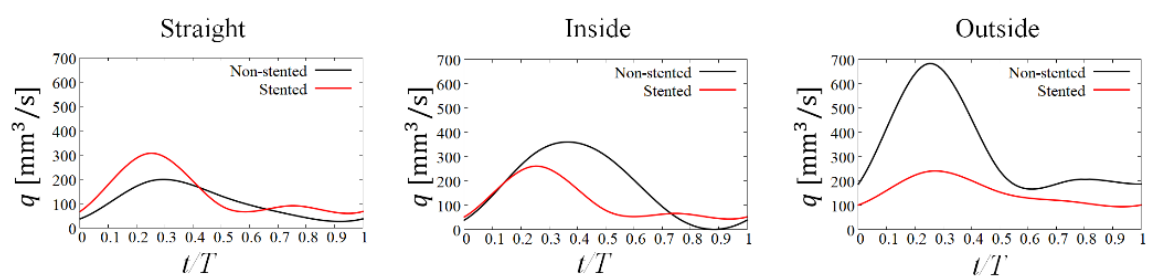

(b) $A R=1.9$

Fig. 6. Time series data depicting inflow rate for a cardiac cycle.

The only case showing a different trend is the straight artery with $A R=1.9$; the maximum flow rate is considerably increased by installing the FD stent.

To investigate the differences in the inflow pattern at the neck, a color contour map of $u_{2}$ (normal-to-theneck velocity) distribution of the neck area at $t / T=0.25$, is shown in Fig. 7. In general, a strong inflow and outflow appeared around the central $(\mathrm{z}=0)$ area and the fluid out-flow in the central area was weak. It is also found that, in the non-stented models, the flow patterns between the $A R=1.2$ and 1.9 models are different in the straight and inside artery cases while they are similar in the outside artery case. Comparisons of the non-stented and stented models reveal that the area where the flow 


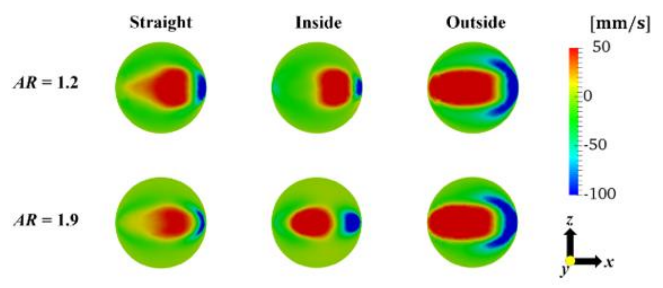

(a) Non-stented

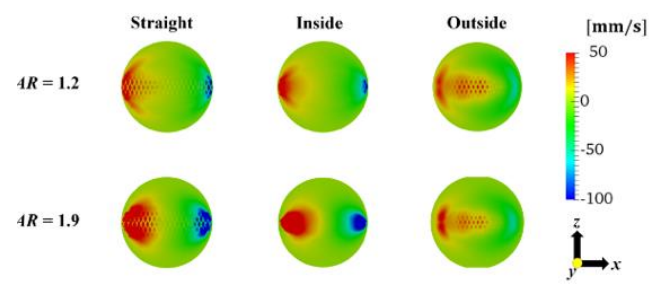

(b) Stented

Fig. 7. Color contour map of the normal-to-theneck (vertical) velocity distribution to the neck area at $\mathrm{t} / \mathrm{T}=\mathbf{0 . 2 5}$.

flows into the aneurysm is significantly changed by stent placement. In the case of the $A R=1.9$ model, the inflow and outflow areas move toward the proximal and distal sides, respectively. Furthermore, strong inflow and outflow areas were enlarged in the case of a stented and straight artery. This increases the inflow rate owing to stent placement. The two areas are also separated in the other two parent artery cases but the size of the areas was considerably reduced by stent placement.

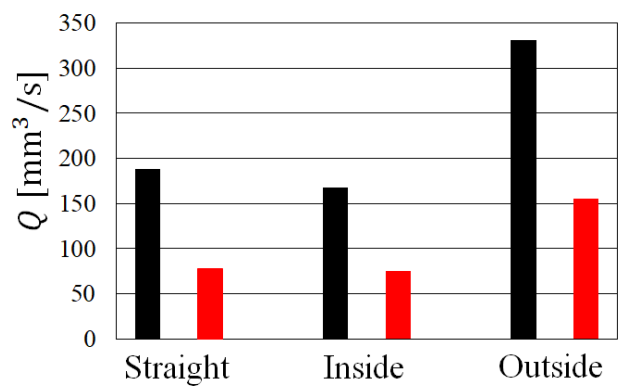

(a)

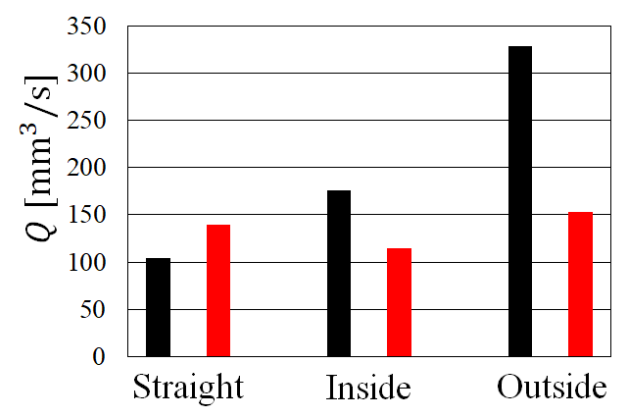

(b)

Fig. 8. Mean inflow rate for a cardiac cycle. (a) $A R=1.2$; (b) $A R=1.9$.

Figure 8 shows the mean inflow rate per cardiac cycle $(Q)$. It is worth noting that although the mean inflow rate is almost the same in some cases, as

indicated previously, this does not mean that the flow patterns are the same. Regarding the effect of stenting, the mean inflow rate is reduced by approximately half in all cases with $A R=1.2$ (Fig. 8(a)). Similarly, for the $A R=1.9$ model (Fig. 8(b)), the mean inflow rate in the inside and outside cases decreased by 35 to $50 \%$. However, the inflow rate increases in the straight artery case, unlike in the other cases. This fact is not intended from a surgical point of view. This may have a bigger impact, considering that stent placement can straighten the parent vessel (Voß et al. 2019; Jeong et al. 2014).

\subsection{Other Hemodynamic-related Statistics}

Figure 9 shows the distribution of wall shear stress. Figures 9 (a) and (b) show the mean wall shear stress (WSS). Note that the maximum WSS in the stented models is significantly lower than that in the nonstented models; thus, the maximum threshold of the color change was set at WSS $=1 \mathrm{~Pa}$ for clearer visualization. For all non-stented models, there exists a high WSS area around the distal side of the neck, where the jet flow enters the aneurysm. For $A R=1.2$, a spotty low WSS area indicated by a black circle appears. The WSS for the $A R=1.9$, model is smaller than that for the $A R=1.2$ model. However, once the stent is placed, the WSS becomes nearly zero in all cases except in the vicinity of the neck.

Wall shear stress as an indicator of aneurysm rupture has been discussed, although the interpretation varies according to different researchers. Some studies have concluded that a high wall shear stress is dangerous (Meng et al. 2007; Boussel et al. 2008) while others concluded that low wall shear stress can cause aneurysm rupture (Jou et al. 2005; Omodaka et al. 2012; Shobayashi et al. 2013; Sindeev et al. 2018; Karmonik et al. 2010. Thus, we do not discuss this topic further here but this fact may imply that other related parameters should be discussed. In this respect, the time fluctuation of the WSS could be important; however, previous studies have only focused on the mean values. For example, the magnitude of variance may be large, even if the mean value is small. Another possibility is that as the movement repeats every second, or more frequently, a short period of spiky behavior, which does not influence the mean value, may significantly affect the vital response. Figure 9I shows the time series data of the WSS at the four locations highlighted in Fig. 9(b). Note that although only the outside cases are shown, the other two cases exhibit the same trend. Figure 9(c) illustrates that, in the present cases, the average and variance show the same tendency, indicating that the fluctuation is small/large when the mean value is small or large.

Furthermore, the oscillatory shear index (OSI) was calculated as the risk index of aneurysm rupture. A high OSI area is thought to cause vascular inflammation due to endothelial disorders (Rajah et al. 2017; Vargas et al. 2016). As shown in Fig. 10, the OSI is generally higher in the stented models than in the non-stented models. In particular, a high OSI area is widely distributed in the aneurysm sac in large aneurysms $(A R=1.9)$ and in straight and inside arteries; i.e., placement of the FD stent has a negative 
Y. Ito et al. / JAFM, Vol. 14, No. 5, pp. 1547-1558, 2021.

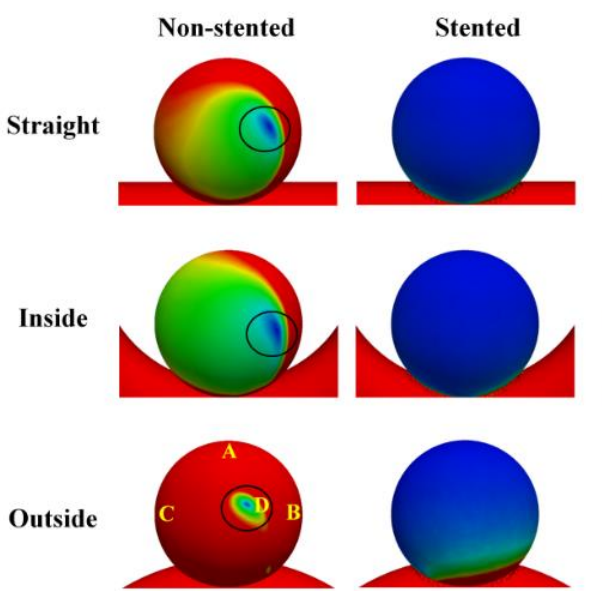

(a) $A R=1.2$

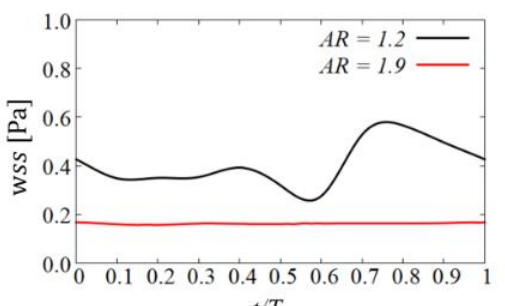

$t / T$

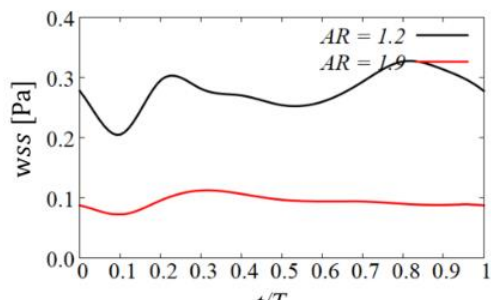

$t / T$
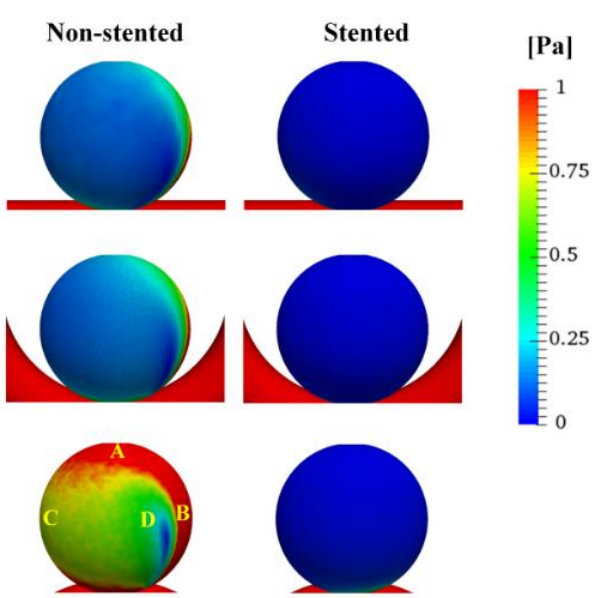

(b) $A R=1.9$

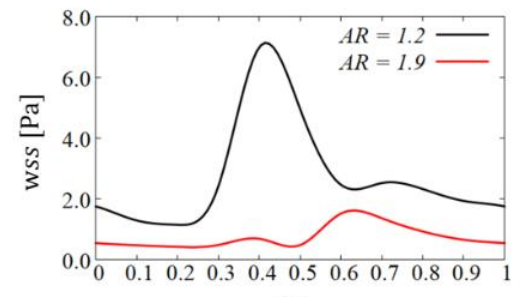

$t / T$

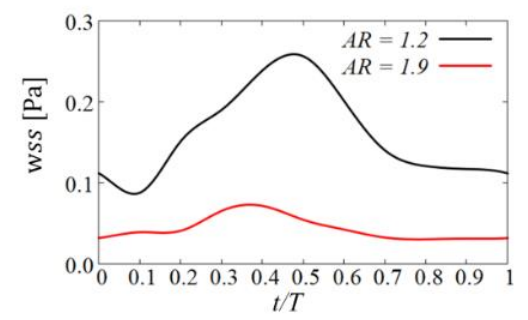

(c)

Fig. 9. Wall shear stress profiles. (a) Mean wall shear stress distribution for $A R=1.2$; (b) Mean wall shear stress distribution for AR=1.9; (c) Time series data of WSS at the four points for the outside case.

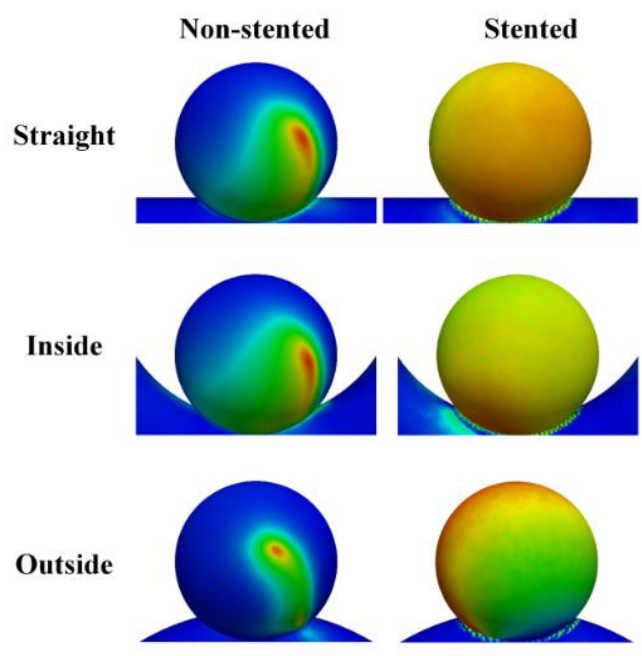

(a) $A R=1.2$
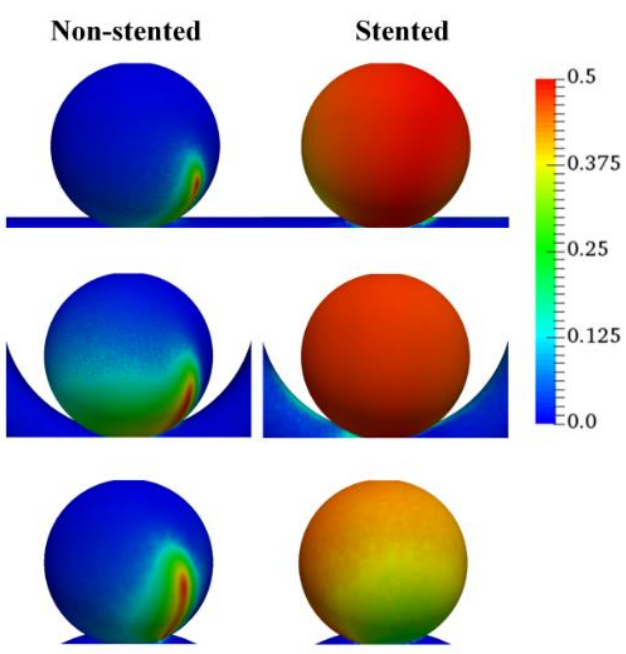

(b) $A R=1.9$

Fig. 10. OSI distributions.

effect from this perspective. It is also notable by comparing Fig. 10 with Fig. 9 that high OSI and low
WSS areas are distributed in almost the same area, particularly in the non-stented models. 


\section{Conclusions}

In this study, we investigated the impact of the placement of a flow diverter (FD) stent as a cerebral aneurysm treatment on hemodynamics in cerebral aneurysms, using a computational fluid dynamics (CFD) simulation. The results reveal that, regardless of the artery shape, the FD stent drastically modifies the flow in the aneurysm, including the change in flow direction. The flow rate into the aneurysm is significantly reduced by the stent in most cases but it is increased in the $A R=1.9$ and straight artery cases. The oscillatory shear index (OSI) generally increases owing to the FD stent placement, whereas the wall shear stress substantially decreases. In particular, a high OSI area is widely distributed in the large aneurysm $(A R=1.9)$ sac for straight and internal artery cases.

Although idealized aneurysm models were employed in the present study, further parametric studies, particularly with respect to the stent configuration (Dmytriw et al. 2019; Moriwaki et al. 2018) are required; these facts possibly explain the unexpected outcome in some (but not all) large aneurysm cases. It is also indicated that both the aneurysm size and artery shape must be considered when estimating the efficacy of FD stent placement.

\section{ACKNOWLEDGEMENTS}

The authors thank Prof. Isoda, M.D., Ph.D., and co-workers at Nagoya University Hospital for their useful discussions.

\section{REFERENCES}

Aenis, M., A. P. Stancampiano, A. K. Wakhloo and B. B. Lieber (1997). Modeling of flow in a straight stented and nonstented side wall aneurysm model. Journal of Biomechanical Engineering 119(2), 206-212.

Anson, M. and L. Zhang (1995, July). On-site graphics for planning and communicating the use of site space. In Y. Loo (Ed.), Proceedings of the Fifth East Asia-Pacific Conference on Structural Engineering and Construction, Gold Coast, Australia, 883-888. Griffith University.

Anzai, H., J. L. Falcone, B. Chopard, T. Hayase and M. Ohta (2014). Optimization of Strut Placement in Flow Diverter Stents for Four Different Aneurysm Configurations. Journal of Biomechanical Engineering 136: 061006.

Berge, J., A. Biondi, P. Machi, H. Brunel, L. Pierot, J. Gabrillargues, et al. (2012). Flow-Diverter Silk Stent for the Treatment of Intracranial Aneurysms 1-year Follow-Up in a Multicenter Study. AJNR 33(6), 1150-1155.

Bhogal, P., R. M. Moreno, O. Ganslandt, H. Bäzner, H. Henkes and M. A. Perez (2017). Use of flow diverters in the treatment of unruptured saccular aneurysms of the anterior cerebral artery. Journal of NeuroInterventional Surgery 9,
283-289.

Bouillot, P., O. Brina, R. Ouared, K. O. Lovblad, M. V. Farhat and M. Pereira (2015). Hemodynamic transition driven by stent porosity in sidewall aneurysms. Journal of Biomechanics 48(7), 1300-1309.

Briganti, F., M. Napoli, F. Tortora, D. Solari, M. Bergui, E. Boccardi, E. Cagliari, L. Castellan, F. Causin, E. Ciceri, L. Cirillo, R. De Blasi, L. Delehaye, F. Di Paola, A. Fontana, R. Gasparotti, G. Guidetti, I. Divenuto, G. Iannucci, M. Isalberti, M. Leonardi, F. Lupo, S. Mangiafico, A. Manto, R. Menozzi, M. Muto, N. P. Nuzzi, R. Papa, B. Petralia, M. Piano, M. Resta, R. Padolecchia, A. Saletti, G. Sirabella and L. P. V. Bolgè (2012). Italian multicenter experience with flow-diverter devices for intracranial unruptured aneurysm treatment with periprocedural complications: a retrospective data analysis. Neuroradiology 54(10), 1145-1152.

Boussel, L., V. Rayz, C. McCulloch, A. Martin, G. Acevedo-Bolton, M. Lawton, et al. (2008). Aneurysm growth occurs at region of low wall shear stress: patient-specific correlation of hemodynamics and growth in a longitudinal study. Stroke 39(11), 2997-3002.

Brinjikji, W., M. H. Murad, G. Lanzino, H. J. Cloft and D. F. Kallmes (2013). Endovascular treatment of intracranial aneurysms with flow diverters: a meta-analysis. Stroke 44(2), 442447.

Cagnazzo, F., P. Perrini, C. Dargazanli, P. H. Lefevre, G. Gascou, R. Morganti, D. di Carlo, I. Derraz, C. Riquelme, A. Bonafe and V. Costalat, (2019). Treatment of Unruptured Distal Anterior Circulation Aneurysms with Flow-Diverter Stents: A Meta-Analysis. AJNR 40, 687-93.

Cebral, J. R., F. Mut, M. Raschi, E. Scrivano, R. Ceratto, P. Lylyk and C. M. Putman (2011). Aneurysm rupture following treatment with flow-diverting stents: computational hemodynamics analysis of treatment. AJNR 32(1), 27-33.

Chong, W., Y. Zhang, Y. Qian, L. Lai, G. Parker and K. Mitchell (2014). Computational hemodynamics analysis of intracranial aneurysms treated with flow diverters: correlation with clinical outcomes. AJNR 35(1), 136-142.

Cognard, C., A. Weill, L. Spelle, M. Piotin, L. Castaings, A. N. Rey and J. Moret (1999). Long-term angiographic follow-up of 169 intracranial berry aneurysms occluded with detachable coils. Radiology 212(2), 348-356.

Connlly, E. S. Jr., A. A. Rabinsten J. R. Carhuapoma, C. P. Derdeyn, J. Dion, R. T. Higashida, B. L. Hoh, C. J. Kirkness, A. M. Naidech, C. S. Ogilvy, A. B. Patel, B. G. Thompson and P. Vespa (2012). Guidelines for the management 
of aneurysmal subarachnoid hemorrhage: a guideline for healthcare professionals from the American Heart Association/American Stroke Assocation. Stroke 43(6), 1711-1737.

Cruz, J. P., M. Chow, C. O'Kelly C, B. Marotta, J. Spears, W. Montanera, D. Fiorella and T. Marotta (2012). Delayed ipsilateral parenchymal hemorrhage following flow diversion for the treatment of anterior circulation aneurysms. AJNR 33(4), 603-608.

De Vries, J., J. Boogaarts, A. Van Norden and A. K. Wakhloo (2013). New generation of Flow Diverter (surpass) for unruptured intracranial aneurysms: a prospective single-center study in 37 patients. Stroke 44(6), 1567-1577.

Dholakia, R., C. Sadasivan, D. J. Fiorella, H. H. Woo and B.B. Lieber (2014). Hemodynamics of flow diverters. Journal of Biomechanical Engineering 139(2), 021002.

Dmytriw, A. A., K. Phan, J. M. Moore, V. M. Pereira, T. Krings and A. J. Thomas (2019). On Flow Diversion: The Changing Landscape of Intracerebral Aneurysm Management. AJNR $40,591-600$

Fischer, S., Z. Vajda, P. M. Aguilar, E. Schmid, N. Hopf, H. Bäzner and H. Henkes (2012). Pipeline embolization device (PED) for neurovascular reconstruction: initial experience in the treatment of 101 intracranial aneurysms and dissections. Neuroradiology 54(4), 369382.

Goel, G., V. Gupta, S. Chinchure, A. Gupta, G. Kaur and A. N. A. Jha (2014). A decade after International Subarachnoid Aneurysm Trial: Coiling as a first choice treatment in the management of intracranial aneurysms Technical feasibility and early management outcomes. Asian Journal of Neurosurgery 9(3), 137-143.

Grunwald, I. Q., P. Papanagiotou, T. Struffert, M. Politi, C. Krick, G. Gül and W. Reith (2007). Recanalization after endovascular treatment of intracerebral aneurysms. Neuroradiology 49(1), 41-47.

Imai, Y., K. Sato, T. Ishihara and T. Yamaguchi (2008). Inflow into Saccular Cerebral Aneurysms at Arterial Bends, Annals of Biomedical Engineering 36(9), 1489-1495

Ishihara, H., S. Ishihara, J. Niimi, H. Neki, Y. Kakehi, N. Uemiya, S. Kohyama and F. Yamane (2015). Risk factors for coil protrusion into the parent artery and associated thromboembolic events following unruptured cerebral aneurysm embolization. Journal of NeuroInterventional Surgery 21(2), 178-183.

Jeong, W., M. H. Han and K. Rhee (2004). The hemodynamic alterations induced by the vascular angular deformation in stent-assisted coiling of bifurcation aneurysms. Computers in Biology and Medicine 53, 1-8.
Jiayao, M., Z. You, T. Peach, J. Byrne and R. A. Rizkallah (2013). New flow diverter stent for direct treatment of intracranial aneurysm. Journal of Biomechanical Engineering 48, 4206-4213.

Jou, L. D., G. Wong, B. Dispensa, M. T. Lawton, R. Higashida, W. L. Young and D. Saloner (2005). Correlation between lumenal geometry changes and hemodynamics in fusiform intracranial aneurysms. AJNR 26(9), 2357-2363.

Karmonik, C., C. Yen, O. Diaz, R. Klucznik, R. G. Grossman and G. Benndorf (2010). Temporal variations of wall shear stress parameters in intracranial aneurysms - importance of patientspecific inflow waveforms for CFD calculations. Acta. Neurochir. 152: 1391-1398.

Kim, M., D. B. Taulbee, M. Tremmel and H. Meng, (2008). Comparison of Two Stents in Modifying Cerebral Aneurysm Hemodynamics, Annals of Biomedical Engineering 36(5), 726741.

Korkmazer, B., B. Kocak, C. Islak, N. Kocer and O. Kizilkilic (2019). Long-term results of flow diversion in the treatment of intracranial aneurysms: a retrospective data analysis of a single center. Acta Neurochirurgica 161, 11651173.

Kulcsar, Z., E. Houdart, A. Bonafe, G. Parker, J. Millar, A. J. Goddart, S. Renowden, G. Gál, B. Turowski, K. Mitchell, F. Gray, M. Rodriguez, R. van den Berg, A. Gruber, H. Desal, I. Wanke and D. A. Rüfenacht (2011). Intra-aneurysmal thrombosis as a possible cause of delayed aneurysm rupture after flow diversion treatment. AJNR 32(1), 20-25.

Lai, S. M., Y. S. Tang, C. O. Tsang, K. K. Leung, C. H. Yu and K. W. Chow (2016), A joint computational-experimental study of intracranial aneurysms: Importance of the aspect ratio. Journal of Hydrodynamics 28(3), 462-472.

Larrabide, I., A. J. Geers, H. G. Morales, P. Bijlengad, and D. A. Rüfenachtea (2016). Change in aneurysmal flow pulsatility after flow diverter treatment, Computerized Medical Imaging and Graphics 50, 2-8

Liou, T. M. and Y. C. Li (2008). Effects of stent porosity on hemodynamics in a sidewall aneurysm model. Journal of Biomechanics. 41(6), 1174-1183.

Lubicz, B., L. Collignon, G. Raphaeli and O. De Witte (2011). Pipeline flow-diverter stent for endovascular treatment of intracranial aneurysms: preliminary experience in 20 patients with 27 aneurysms. World Neurosurg. 76(1-2), 114-119.

Lubicz, B., L. Collignon, G. Raphaeli, J. P. Pruvo, M. Bruneau, O. De Witte and X. Leclerc (2010). Flow-diverter stent for the endovascular treatment of intracranial aneurysms a prospective study in 29 patients with 34 
aneurysms. Stroke 41(10), 2247-2253.

Lylyk, P., C. Miranda, R. Ceratto, A. Ferrario, E. Scrivano, H. R. Luna, A. L. Berez, Q. Tran, P. K. Nelson and D. Fiorella (2009). Curative endovascular reconstruction of cerebral aneurysms with the Pipeline embolization device: the Buenos Aires experience. Neurosurgery 64(4), 642-643.

Matsuda, T., Y. Ito, K. Masunaga, Y. Sakai, K. Irie, K. Iwano and K. Nagata. (2017). Modification of hemodynamics in basilar artery aneurysm by the single and $\mathrm{Y}$ stent placement. Technol. Health Care 25(5), 832-842.

McDonald, J. S., J. McDonald, J. Fan, D. F. Kallmes, G. Lanzino and H. J. Cloft (2014). Comparatice effectiveness of ruptured cerebral aneurysm therapies: propensity score analysis of clipping versus coiling. AJNR 35(1), 164169.

Meng, H., Z. Wang, M. Kim, R. D. Ecker and L. N. Hopkins (2006). Saccular Aneurysms on Straight and Curved Vessels Are Subject to Different Hemodynamics: Implications of Intravascular Stenting, AJNR. 27(9), 18611865

Meng, H., Z. Wang, Y. Hoi, L. Gao, E. Metaxa and D. D. Swartz and J. Kolega (2007). Complex hemodynamcis at the apex of an arterial bifurcation induce vascular remodeling resembling cerebral aneurysm initiation. Stroke 38(6), 1924-1931.

Möhlenbruch, M. A., C. Herweh, L. Jestaed, S. Stampfl, S. Schönenberger, P. A. Ringleb, M. Bendszus and M. Pham (2015). The FRED flow-diverter stent for intracranial aneurysms: clinical study to assess safety and efficacy. AJNR 36(6), 1155-1161.

Mori, F., S. Hanida, M. Ohta and T. Matsuzawa (2014). Effect of parent artery expansion by stent placement in cerebral aneurysms. Technol. Health care 22(2), 209-223.

Moriwaki, T., T. Tajikawa and Y. Nakayama (2018). Hydrodynamical evaluation of microporous covered stent for the treatment of intracranial aneurysms: Comparison of flow reduction property with flow diverter stent by using particle imaging velocimetry and in vitro flow simulator. Journal of Biorheology. 32(1), 20-25

Mustafa, W., K. Kadziolka, R. Anxionnat and L. Pierot (2010). Direct carotid-carvernous fistula following intracavernous carotid aneurysm treatment with a flow-diverter stent. A case report. Interv. Neuroradiol. 16(4), 447-450.

Nelson, P. K., P. Lylyk, I. Szikora, S. G. Wetzel, I. Wanke and D. Fiorella (2011). The pipeline embolization device for the intracranial treatment of aneurysms trial. AJNR 32(1), 3440.

Omodaka, S., S. Sugiyama, T. Inoue, K. Funamoto, M. Fujimura, H. Shimizu, et al.
(2012). Local hemodynamics at the rupture point of cerebral aneurysms determined by computational fluid dynamics analysis. Cerebrovascular Diseases 34(2), 121-129.

Rajah, G., S. Narayanan and L. Rangel-Castilla (2017). Update on flow diverters for the endovascular management of cerebral aneurysms. Neurosurgical Focus 42(6), E2.

Piano, M., L. Valvassori, L. Quilici, G. Pero and E. Boccardi (2013). Midterm and long-term follow-up of cerebral aneurysms treated with flow diverter devices: a single-center experience. Journal of Neurosurgery 118(2), 408-416.

Pierot, L., L. Spelle, C. Leclerc, C. Cognard, A. Bonafe and J. Moret (2014). Endovascular treatment of unruptured intracranial aneurysms: comparison of safety of remodeling technique and standard treatment with coils. Radiology 251(3), 846-855.

Piotin, M., R. Blanc, L. Spelle, C. Mounayer, R. Piantino, P. J. Schmidt and J. Moret (2010). Stent-assisted coiling of intracranial aneurysms: clinical and angiographic results in 216 consecutive aneurysms. Stroke 41(1), 110-115.

Rouchaud, A., W. Brinjikji, G. Lanzino, H. J. Cloft, R. Kadirvel and D. F. Kallmes (2016). Delayed hemorrhagic complications after flow diversion for intracranial aneurysms: a literature overview. Neuroradiology 58(2), 171-177.

Saatci, I., K. Yavuz, C. Ozer, S. Geyik and H. S. Cekirge (2012). Treatment of intracranial aneurysms using the pipeline flow-diverter embolization device: a single-center experience with long-term follow-up results. AJNR 33(8), 1436-1446.

Sadasivan, C., L. Cesar, J. Seong, A. Rakian Q. Hao, F. O. Tio, A. K. Wakhloo and B. B. Lieber (2009). An Original Flow Diversion Device for the Treatment of Intracranial Aneurysms Evaluation in the Rabbit ElastaseInduced Model. Stroke 40(3), 952-958.

Seshadhri, S., G. Janiga, O. Beuing, M. Skalej and D. Thévenin (2011). Impact of stents and flow diverters on hemodynamics in idealized aneurysm models. Journal of Biomechanical Engineering 133(7), 71005.

Seong, J., A. K. Wakhloo and B. B. Lieber (2007). In vitro evaluation of flow divertors in an elastase-induced saccular aneurysm model in rabbit. Journal of Biomechanical Engineering 129(6), 863-872.

Shapiro, M., T. Becske, D. Sahlein D, J. Babb and P. K. Nelson (2012). Stent-supported aneurysm coiling: a literature survey of treatment and follow-up. AJNR 33(1), 159-163.

Soeda, A., N. Sakai, H. Sakai, K. Iihara, N. Yamada, S. Imakita and I. Nagata (2003). Thromboembolic events associated with Guglielmi detachable coil embolization of 
Y. Ito et al. / JAFM, Vol. 14, No. 5, pp. 1547-1558, 2021.

asymptomatic cerebral aneurysms: evaluation of 66 consecutive cases with use of diffusionweighted MR imaging. AJNR 24(1), 127-132.

Shobayashi, Y., S. Tateshima, R. Kakizaki, R. Sudo, K. Tanishita and F. Viñuela (2013). Intraaneurysmal hemodynamic alterations by a selfexpandable intracranial stent and flow diversion stent: high intra-aneurysmal pressure remains regardless of flow velocity reduction. Journal of NeuroInterventional Surgery 5: iii38-iii42.

Siddiqui, A.H., A. A. Abla, P. Kan, T. M. Dumont, S. Jahshan, G. W. Britz, L. N. Hopkins and E. I. Levy (2012). Panacea or problem: flow diverters in the treatment of symptomatic large or giant fusiform vertebrobasilar aneurysms. Journal of Neurosurgery 116(6), 1258-1266.

Sindeev, S., P. G. Arnold, S. Frolov, S. Prothmann, D. Liepsch, A. Balasso, P. Berg, S. Kaczmarz and J. S. Kirschke (2018). Phase-contrast MRI versus numerical simulation to quantify hemodynamical changes in cerebral aneurysms after flow diverter treatment. PLOS One 13(1), e0190696.

Tateshima, S., Y. Murayama, J. P. Villablanca, T. Morino, K. Nomura, K. Tanishita and F. Viñuela (2003). In vitro measurement of fluidinduced wall shear stress in unruptured cerebral aneurysms harboring blebs. Stroke 34(1), 182192.
Torres, F. G., F. Roca, A. Noguera, J. Godes, S. Petrocelli, I. Aznar, et al. (2018). Silk flowdiverter stent for the treatment of complex intracranial aneurysms: A one-year follow-up multicenter study. Interventional Neuroradiology 24(4), 352-362.

Turowski, B., S. Macht, Z, Kulcsar, D. and Hanggi, W. Stummer (2011). Early fatal hemorrhage after endovascular vertebral aneurysm treatment with a flow diverter (SILK-Stent), do we need to rethink our concepts? Neuroradiology 53(1), 37-41.

Ujiie, H., Y. Tamano, K. Sasaki and T. Hori (2011). Is the aspect ratio a reliable index for predicting the rupture of a saccular aneurysm? Neurosurgery 48(3), 495-503.

Vargas, S.A., C. Diaz, D.A. Herrera and A.B. Dublin (2016). Intracranial Aneurysms in Children: The Role of Stenting, and Flow-Diversion. Journal of Neuroimaging 26, 41-45.

Voß, S., O. Beuing, G. Janiga and P. Berg (2019). Stent-induced vessel deformation after intracranial aneurysm treatment - A hemodynamic pilot study. Computers in Biology and Medicine 111, 103338.

Walcott, B. P., C. J. Stapleton, O. Choudhr and A. B. Patel (2016). Flow Diversion for the Treatment of Intracranial Aneurysms. JAMA Neurol. 73(8), 1002-1008 